\title{
DOCUMENTOS
}

El texto que sigue, ha sido elaborado, a petición del Padre General de la Compañía de Jesús, por un grupo de jesuitas relacionados con el Oriente Próximo. Es ante todo una llamada a la conciencia personal de cada uno, ante lo que viven muchos cristianos del Oriente Próximo en el día de hoy.

Deseamos que pueda servir para un intercambio de ideas y animar también a todos aquellos y aquellas que estén abiertos a la preocupación del futuro de los pueblos de la región, en las iniciativas concretas que pudieran tomar.

\section{Recuperar la palabra en Medio Oriente}

\section{Grupo de reflexión de la Compañía de Jesús}

1. La situación dramática que vivimos actualmente en Oriente Medio tiene su origen en los conflictos locales, regionales e internacionales, en la competitividad entre las potencias mundiales por hacerse con los recursos de la región y en las luchas internas por la justicia social, por la libertad y por el establecimiento de unos regímenes políticos que respeten la dignidad humana. Esta dramática situación nos sume frecuentemente en una mezcla de desánimo ante la locura criminal, de cansancio extremo ante una paz que parece inalcanzable y de impotencia para actuar en un contexto geopolítico difícil de entender. Las distintas partes de estas sociedades, sufren el influjo de esta locura, comenzando por las comunidades cristianas, musulmanas y judías, particularmente en Palestina, Siria, Irak, Libia y Yemen, pero también en un grado o en otro, en muchos otros países de la región. Ante este drama, tenemos que romper el silencio y despertar las conciencias individuales y la de la comunidad internacional. 


\section{Primera parte: una situación alarmante}

2. La gravedad y la precariedad de la situación en la que se encuentran los pueblos de los países en conflicto aparecen claramente en las cifras suministradas por las agencias internacionales. Por no citar más que el caso de Siria, según $\mathrm{OCHA}^{1}$, 13,5 millones de sirios (sobre una población estimada en 2010 en 22 millones de habitantes) necesitan ayuda humanitaria, 4,8 millones han salido del país para refugiarse en los países vecinos o en Europa, y 6,6 millones están desplazados en el interior de su país a causa de la violencia.

3. Evidentemente las comunidades cristianas figuran entre las que sufren esta situación catastrófica. Dos declaraciones recientes firmadas por el Papa Francisco, una con el Patriarca Bartolomé, el 25 de marzo de 2014, y otra con el Patriarca Cirilo el 12 de febrero de 2016, han arrojado luz sobre esta situación. La primera declaración alertaba precisamente sobre la situación de las Iglesias en Egipto, en Siria y en Irak, que han sufrido más dolorosamente en razón de los sucesos recientes $^{2}$. La segunda declaración subrayaba igualmente el hecho que

en numerosos países del Oriente Próximo y de África del norte, nuestros hermanos y hermanas en Cristo son exterminados por familias, ciudades y pueblos enteros. Sus iglesias son destruidas y saqueadas de forma salvaje, sus objetos sagrados profanados, sus monumentos destruidos. En Siria, en Irak y en otros países del Oriente Próximo, observamos con dolor el éxodo masivo de cristianos de la tierra en la que comenzó a propagarse nuestra fe y en donde vivieron desde los tiempos apostólicos en unión con otras comunidades religiosas ${ }^{3}$.

4. Por primera vez en la historia de la ONU, el Consejo de Seguridad se reunió el 27 de marzo de 2015 dedicando la sesión a la situación de los cristianos de Oriente y a otras minorías. En el transcurso de la sesión, el Secretario General de la ONU, señor Ban Ki-Moon, habló de los grandes peligros a los que están

\footnotetext{
1 Información dada por el United Nations Office for the Coordination of Humanitarian Affairs http:// www.unocha.org/syria (sitio consultado el 14 de junio de 2016).

2 Declaración conjunta del Papa Francisco y del Patriarca Bartolomé, n. 8 (Jerusalén, 25 de mayo de 2014): http://w2.vatican.va/content/francesco/fr/speeches/2014/may/documents/papafrancesco_20140525_terra-santa-dichiarazione-congiunta.html (sitio consultado el 14 de junio de 2016).

${ }^{3}$ Declaración común del Papa Francisco y del Patriarca Cirilo de Moscú y de toda Rusia, n. 8 (La Habana el 12 de febrero de 2016: http://w2.vatican.va/content/francesco/fr/speeches/2016/ february/documents/papa-francesco_20160212_dichiarazione-comune-kirill.html (sitio consultado el 14 de junio de 2016).
} 
expuestas las minorías de ciertos países del Medio Oriente, añadiendo que están en juego millones de vidas humanas y el tejido social de países enteros ${ }^{4}$.

5. Estas declaraciones e iniciativas manifiestan, entre otras cosas, hasta qué punto la presencia milenaria de los cristianos en Oriente ve gravemente amenazado su futuro. Según la estimación del informe del Secretario General del Sínodo de los obispos para Medio Oriente en $2010^{5}$, la región podía contar en esa fecha con alrededor de 20 millones de cristianos (5,62\% de la población), de los cuales 5,7 millones eran católicos (1,60\% de la población) repartidos en los 16 países, además de Jerusalén y los territorios palestinos: Arabia Saudita, Bahréin, Chipre, Egipto, Emiratos Árabes Unidos, Irán, Irak, Israel, Jordania, Kuwait, Líbano, Omar, Qatar, Siria, Turquía y Yemen. Desde entonces, la situación no ha hecho más que deteriorarse en numerosos países.

6. Frente a esta situación, los cristianos de todo el Oriente Próximo, en particular en el Líbano, en Jordania, en Palestina y en Egipto son presa de profunda angustia y de gran inquietud por su futuro. Muchos han emigrado y son numerosos los que esperan una ocasión que les permita emprender definitivamente el camino del exilio en Occidente.

\section{I. Los orígenes de esta dolorosa situación}

7. Distintas razones explican las dificultades que viven los cristianos. A veces se les identifica con Occidente, frente al que muchos musulmanes experimentan un profundo resentimiento desde la caída del imperio otomano, pero sobre todo después de la creación del estado de Israel y del nacimiento del conflicto árabe-israelita. Otras veces se les ataca simplemente porque son el elemento más débil de la sociedad, y son acusados de apoyar a los regímenes locales. No rara vez es el hecho mismo de ser cristianos lo que resulta insoportable para los elementos islámicos más radicalizados. De este modo los cristianos acaban por ser el blanco natural de la violencia que desgarra a los países del Medio

\footnotetext{
${ }^{4}$ Naciones Unidas-Consejo de Seguridad, sesión del 27 de marzo de 2015 sobre la situación del Medio-Oriente (víctimas de ataques y de exacciones étnicas o religiosas en el Medio-Oriente). Ver: http://www.un.org/press/fr/2015/CS1 1840.doc.htm (sitio consultado el 14 de junio de 2016).

${ }^{5}$ Cf. Informe del Secretario General del Sínodo de los obispos (Mons. Nikola Eterovic), La Iglesia Católica en el Medio-Oriente: Comunión y testimonio, Ciudad del Vaticano, 2010, p. 7 en: http:// www.vatican.va/roman_curia/synod/documents/rc_synod_doc_20101010_relazione-seg-gen_fr.pdf (sitio consultado el 14 de junio de 2016).
} 
Oriente. Violencia ciega que no deja fuera a ninguno de los que componen las sociedades de estos países.

8. Tras la esperanza que despertaron "las primaveras árabes" del 2011, los cristianos, como también una gran parte de los habitantes de la región, se hallan hoy día en medio de una gran confusión. Si la situación actual ha llegado a ser de relativa estabilidad en Egipto, sigue siendo explosiva en Irak, en Siria, en Yemen y en Libia, donde el escenario militar se hace cada vez más internacional. No podemos olvidar tampoco la situación en Tierra Santa, donde la ausencia de estatuto político suscita la tensión permanente entre palestinos e israelíes, origen de la violencia que padecen ambos pueblos.

\section{I.2. Grandes esperanzas}

9. A pesar de todo la tragedia de los cristianos de Oriente y de todos los pueblos árabes, no debe impedirnos vislumbrar un signo de esperanza en las sublevaciones populares que se han producido. ¿¿Cuál es su significado? La población de esta región desea una vida mejor; los regímenes que se han sucedido no han logrado acelerar el progreso de sus respectivas sociedades; el Islam político, que ha sido a menudo la única fuerza de oposición organizada, ha fracasado totalmente en su intento de producir un sistema de gobierno capaz de integrar los principios de la modernidad. Cuando comenzaron los levantamientos, la población esgrimía el eslogan de la dignidad, manifestando así el deseo de emancipación que se nutría de los valores de la modernidad, la democracia, los derechos del hombre, la justicia social y de la apertura cultural que los medios de comunicación ponían a su alcance. Esos levantamientos no han tenido una traducción concreta y eficaz en programas económicos ni políticos. La persistente debilidad de las autoridades centrales frente a los desafíos de cada país, y la ausencia de una oposición con política clara y unificada, han dejado dramáticamente paso al caos, al surgir de extremismos y a intervenciones exteriores.

\section{Segunda parte: toma de conciencia para construir el futuro}

10. Escuchamos el grito de estos hombres y mujeres, cristianos, musulmanes y de otras confesiones. Sufrimos con ellos la violencia activa y la pérdida de confianza en el futuro. Pero tampoco podemos contentarnos con permanecer constatando sin más el drama que se desarrolla ante nuestros ojos. La esperanza y la responsabi- 
lidad cristianas nos empujan a trabajar con otros para que las fuerzas de división y de muerte no continúen su acción destructiva.

\section{I. La palabra en el corazón de lo político}

11. La crisis del Medio Oriente es ante todo una crisis de la Palabra. Palabra confiscada, incluso amordazada, palabra truncada $\circ$ mentirosa, palabra desconectada de la vida de las gentes... que ha conducido a un desfalco más - menos total de lo político y ha gangrenado también las esferas culturales y religiosas. Las poblaciones de la región tienen una gran aspiración a tener por fin derecho a la palabra. Esta libertad de expresión se ha reivindicado por ejemplo en la vida política, a menudo pervertida por el clientelismo, el dominio del clan, la corrupción y la instrumentalización de las religiones. En lo que toca a la economía es con frecuencia objeto de control por parte de los estamentos próximos al poder. A menudo se invocan la democracia y la transparencia, instrumentalizándolas en los discursos y proclamas solemnes, pero ni se desean ni se promueven. Las minorías se encuentran pronto en la periferia de la vida nacional, a lo más se las tolera, se sospecha constantemente de ellas y se las acusa de estar implicadas en el momento en que la inestabilidad política se apodera de los países.

12. La educación para la democracia exige la implicación de todos, comenzando por las autoridades políticas del país. Pero también de todas las instituciones educativas. Es en efecto por medio de la cultura, del conocimiento y el encuentro con otros, como podrán desaparecer la desconfianza, los prejuicios y la lectura simplista de la realidad, y podrá así tejerse un cuerpo social. Es urgente, desde el punto de vista ciudadano y educativo aprender a escucharse, a hablarse, a respetar a los demás, a dar el lugar justo tanto a la persona como a la comunidad, a gestionar los conflictos. La educación ciudadana supone un verdadero aprendizaje en los derechos del hombre y una reflexión sobre la noción de laicidad (en el sentido de una ciudadanía que reconoce y respeta la pluralidad cultural y religiosa). Solamente bajo esta condición, la religión encontrará su justo lugar en el espacio público y permitirá una contribución positiva para la convivencia.

13. La vida política es a menudo rehén de grupos que se han apoderado del poder. En estas ocasiones el repliegue sobre la propia comunidad de pertenencia aparece a menudo como la solución menos mala. Un guion posible sería permitir un acceso verdadero de hombres y mujeres representativos a las responsabilidades políticas, permitiendo así una renovación de las clases dirigentes. Esta perspectiva 
puede parecer inalcanzable en muchos países. Pero aunque sea algo que necesita tiempo, es un objetivo al que hay que dar prioridad en nuestro trabajo.

14. Es vital para nuestros países descubrir la importancia de la noción del bien común e inscribirlo en el derecho y en las prácticas políticas y económicas. Esto supone trabajar por lograr cambiar la mentalidad y las estructuras de la vida común, para defender que todos tenemos igual dignidad.

\subsection{Urgencia de una renovación espiritual y religiosa}

15. La situación del Medio-Oriente manifiesta al mismo tiempo una crisis espiritual y religiosa. Los dramas que conoce la región, la reducción del espacio público, las dificultades económicas persistentes, llevan a que muchas personas tengan, como únicos lugares de afirmación de su identidad humana y espiritual, los ritos y las tradiciones de su propia comunidad. Muchos no ven ya sentido de su existencia, $y$ han perdido la confianza en sus responsables religiosos.

16. La imbricación de lo religioso en lo político ha contribuido desde hace tiempo a confundir responsabilidades e intereses. En muchas situaciones son los responsables religiosos los que desempeñan un papel político. Y numerosos problemas, que son ante todo políticos, no habiendo sido tratados como tales, han abandonado este registro poco a poco para pasar al religioso, con todos los riesgos que ello comporta de "comunitarización" e incluso de radicalización.

\subsection{La identidad cristiana}

17. La presencia cristiana en la región recibe también una fuerte sacudida. ¿Qué significa ser cristiano hoy en esta región del Oriente Medio, testigo del nacimiento del cristianismo? ¿¿Qué significa seguir a Cristo en el contexto actual? ¿ ¿Qué cristianos formamos? ¿Qué testimonio damos de la verdad y de la justicia?

18. La identidad cristiana no puede ser solo una identidad en oposición a otra (ser cristiano porque no se es musulmán o no se es judío), ni ser solamente custodia de una tradición ritual y litúrgica, por muy importante que ello sea, ni tampoco puede convertirse en un valor añadido para poder emigrar, sino más bien una afirmación positiva, consciente, y renovada de una verdadera experiencia espiritual personal y eclesial. 
19. Como diferentes Sínodos y Asambleas de las Iglesias de Oriente ${ }^{6}$ han proclamado ya más de una vez, esta invitación a la renovación espiritual y teológica pasa, de un modo u otro, por optar verdaderamente por el diálogo y el debate en el interior mismo de las Iglesias, incluso comenzando por sus pastores, por la calidad del testimonio, la preocupación por una simplicidad de vida vivida según el espíritu del Evangelio y por una distancia profética con respecto al poder. Debe pasar igualmente por la voluntad real y valiente de unidad entre las Iglesias, de la que el pueblo cristiano tiene tanta necesidad.

\subsection{El compromiso cristiano}

20. Este compromiso cristiano pasa por desarrollar una teología de la "resistencia espiritual". Esto significa profundizar en aquella pertenencia personal y comunitaria a Cristo que devuelve el sentido a una presencia quizá frágil, debido a la violencia y la intolerancia, o amenazada por las corrientes individualistas y consumistas. Este enraizamiento espiritual será portador de un ánimo renovado que manifieste la atención, la proximidad, y la misericordia de Dios en las diferentes realidades de la sociedad, especialmente en la educación, la salud, y el desarrollo. Al elegir un compromiso nuevo con esta vía de apertura que supera los repliegues comunitarios y confesionales, la lglesia del Medio Oriente se siente portadora de valores humanos al servicio de todos los ciudadanos, en particular de los más débiles de la sociedad.

\subsection{Con los musulmanes}

21. El fundamentalismo musulmán, la radicalización de ciertas corrientes del Islam y la locura de grupos como el Estado Islámico, constituyen causas muy legítimas de miedo para los cristianos. En ciertos países, las persecuciones son importantes, la violencia anticristiana notoria, y el hecho de vivir juntos se presenta como un recuerdo perdido. Pero no tenemos que olvidar que muchos musulmanes son también víctimas de este extremismo surgido dentro de su propia religión. La grave crisis que conoce el Islam, va más allá del Medio Oriente y atañe al mundo entero. Se ha hecho difícil saber de qué Islam estamos hablando, ya que las situaciones,

\footnotetext{
- Ver: Consejo de los Patriarcas Católicos de ORIente, Juntos ante Dios por el bien de la persona y de la sociedad (sobre la coexistencia entre musulmanes y cristianos en el mundo árabe), $3^{a}$ Carta Pastoral de los Patriarcas Católicos de Oriente dirigida a sus fieles, en Oriente y en la Diáspora, Navidad 1994. (http://www.cpco.me/fr/images/3e_lettre_fr.pdf)
} 
las referencias, las pertenencias... son numerosas y complejas. Pero en el centro de esta crisis todos los musulmanes tienen planeada la cuestión de la relación de su religión con la historia, con la modernidad y su capacidad para iniciar un verdadero trabajo de interpretación de los textos sagrados. Es preciso encontrar el camino para un verdadero diálogo que renuncie a la violencia entre las dos corrientes mayoritarias del Islam: el Sunismo y el Chiismo.

22. Más que nunca conviene facilitar, mientras aún es posible, aunque sea en forma modesta, que se organicen encuentros. Lo que hace descender el miedo y recuperar la confianza es el conocimiento personal del otro. Tenemos que entablar juntos el combate para propiciar un estado de derecho, democrático, respetuoso con las legítimas aspiraciones de las personas y de los grupos que lo constituyen. Los cristianos, que en la historia de la región han participado en el Renacimiento cultural, intelectual y artístico árabe (AI Nahda en los siglos XIX y XX), y se han mostrado activos en el cambio social, tienen todavía mucho que aportar, para escribir una nueva página de la vida de esta región. Su presencia será precisamente preciosa para poder compartir con los musulmanes este cometido de decir una palabra liberadora, impidiendo el riesgo de colapso que provocaría la desaparición de la alteridad.

\subsection{La responsabilidad internacional}

23. No es posible contemplar esta región, presa de dramas violentos y criminales, haciendo abstracción de influencias y responsabilidades regionales e internacionales. La voluntad de lograr la paz y la estabilidad va más allá de la sola responsabilidad de los actores locales. Es legítimo poner en cuestión la política que se ha puesto en práctica, los intereses en juego, el tipo de financiamiento empleado por parte de unos y otros y que han conducido a la situación que conocemos.

24. Cien años después de los acuerdos Sykes-Picot que trazaron los contornos de la región en sus grandes líneas, parece que estamos otra vez en una época en la que se buscan nuevos trazados y nuevos equilibrios, con el riesgo de que los cambios de fronteras y la destrucción de países, debiliten todavía más las comunidades minoritarias e impidan la convivencia. La responsabilidad de las potencias implicadas y de la comunidad internacional en su conjunto, tiene la obligación de salir de un cierto maquiavelismo, de su pasividad y unas disputas ideológicas que sólo provocan que se agrave el desastre humano, moral y cultural tan fuerte que vive el Medio Oriente desde hace mucho tiempo. De esta manera, la regulación justa y digna del problema palestino-israelí, desde hace tiempo relegado, y que ha 
minado toda la región desde hace decenios, ayudará a abrir nuevas perspectivas de entendimiento y de vida en común.

25. La opción por el diálogo y cuidar la calidad de nuestra palabra con los demás, es la primera etapa de un largo proceso de reconstrucción de una región, en la que los cristianos tienen gran importancia y que tiene mucho que aportar a sus habitantes y al mundo.

Junio 2016

(Texto original: francés)

\section{SALTERRAE}

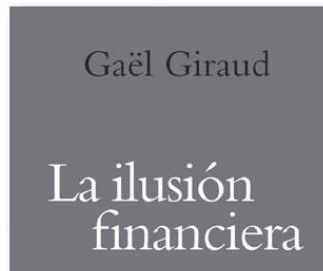

GAËL GIRAUD

Lailusión financiera

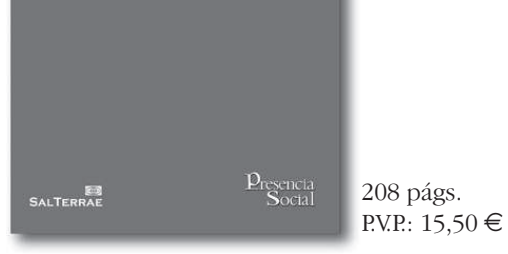

Desde el año 2010, la crisis financiera de los créditos subprime se ha transformado en una crisis de la deuda pública de los diferentes países, y todo parece indicar que lo peor está aún por llegar. El callejón sin salida en que los mercados financieros encierran a la economía europea llega incluso a poner en entredicho a las instituciones mismas que rigen la vida en común europea. ¿Existen otras soluciones que no sean la generalización de los planes de austeridad presupuestaria, el pago de la deuda bancaria por los contribuyentes y la deflación? Publicado en Francia en 2012, este libro ha sido objeto de infinidad de artículos de prensa que han subrayado la claridad y la audacia de las afirmaciones de su autor.

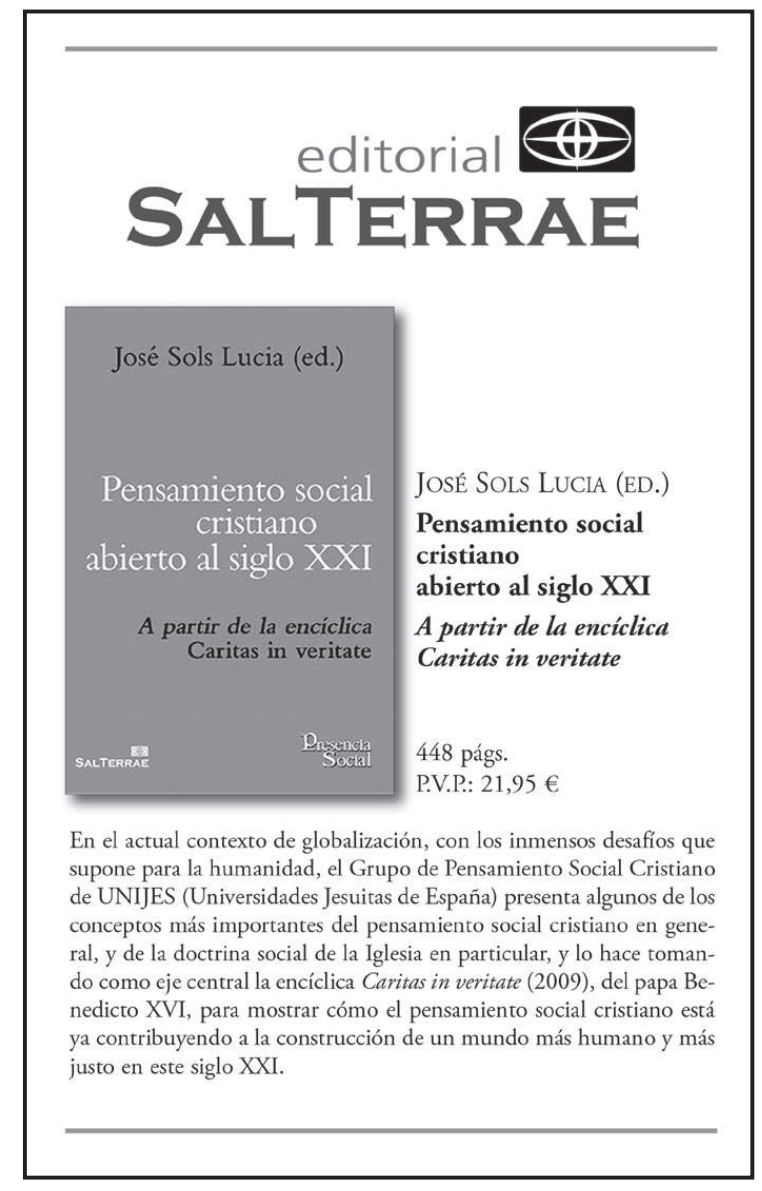




\section{Comentario}

\section{Gonzalo Villagrán Medina S.I.'}

El reciente documento Medio Oriente: Recuperar la palabra, escrito por un grupo de expertos a petición de Adolfo Nicolás, prepósito general de la Compañía de Jesús, sobre la situación de los cristianos en la actual crisis de Oriente Medio supone una muy buena descripción del contexto del diálogo islamo-cristiano en la actualidad.

1. Lo primero que hay que señalar en el documento es la honda toma de conciencia ante la situación de crisis, violencia y opresión existente en Oriente medio que conlleva una enorme injusticia principalmente para los cristianos de aquella tierra, aunque en muchas ocasiones afecte también a los propios musulmanes. El diálogo islamo-cristiano actual tiene que saberse en un escenario de crisis y de urgencia que no permite entenderlo de manera abstracta y alejada de la realidad, sino que exige dirigir los esfuerzos a poner paz en esa situación.

Por otra parte, centrar la mirada en la situación de intolerable injusticia de las comunidades cristianas de Oriente medio nos obliga a superar una mirada eurocentrista tan sólo preocupada ante la amenaza terrorista a nuestra seguridad como europeos. Igualmente, nos obliga a sacudirnos de encima cualquier ingenuidad o irenismo simplista en el encuentro con nuestros hermanos musulmanes. Creemos en la necesidad y la bondad del diálogo, pero éste debe incluir una mirada a la realidad que saque a la luz las situaciones de injusticia y las ponga sobre la mesa, lo que debe ser un acicate para un diálogo más realista y más esforzado a la vez.

2. En segundo lugar, está claro que el documento sitúa en el centro del diálogo islamo-cristiano la visión de la política de ambas tradiciones religiosas, y no tanto los grandes principios teológicos. El diálogo islamo-cristiano actual ha de esforzarse en dialogar sobre los grandes principios de una vida política justa y ha de ser un diálogo que busque para cada tradición religiosa una sana apropiación de aquellos principios, que no son de ninguna tradición concreta sino son fruto del avance moral en la historia de la humanidad. Esta apropiación debe hacerse

' Facultad de Teología, Granada. Miembro de la Cátedra andaluza de diálogo interreligioso (CANDIR) y del Grupo PLURIEL, Lyon (Francia). 
desde el interior de la propia tradición religiosa y desde las propias fuentes; si no, aquél se limitará a ser un barniz que no cambie el fondo de las mentalidades. Podemos tomar como ejemplo el largo y complejo proceso de recepción y aceptación de la democracia por parte de la Iglesia católica que culminó con la encíclica Pacem in Terris en 1963. Este proceso nos habla del largo camino que tiene la tradición islámica por delante para acoger plenamente valores como éste, e igualmente de la posibilidad real de que ese camino se dé, por lo que hay que destacar las bases ya existentes en el Islam para acoger estos valores como el concepto de shûra (consenso) como forma de resolver problemas de la umma por la participación de muchos. Algo tan propio de la democracia occidental como el hecho de votar para elegir gobierno no es ningún problema para la legislación islámica (M. KüNKLER, 2013).

Se percibe claramente que el reto es poder tener una comprensión común de valores como la dignidad humana, la libertad religiosa o la democracia. ${ }^{2}$ De hecho, como bien dice el documento, estos son los anhelos primeros que movilizaron a las poblaciones en el comienzo de las primaveras árabes, estos anhelos ni se han cumplido ni han dejado de estar presentes.

3. En tercer lugar, como bien dice el título del documento, lo que necesitamos es "recuperar la palabra", es decir volver a experimentar el diálogo como algo efectivo y útil. Muchos, ante las situaciones de violencia, injusticia y manipulación política de la religión, concluyen que el diálogo interreligioso ha sido una postura ingenua e infantil de otros tiempos más optimistas. Para estas personas habría que desarrollar un realismo pétreo capaz de hacer frente con dureza a la dureza del otro. Ciertamente el diálogo interreligioso debe integrar la experiencia de fracaso que esta crisis supone, pero aun así, al final sólo el diálogo puede ayudarnos a salir de aquí.

Actualmente existe una segunda generación de teólogos dedicada el diálogo interreligioso, que quiere romper con una primera que habría desarrollado una postura más ingenua. Estos autores intentan integrar en sus modelos de diálogo la realidad de la incomprensión, de la diferencia, o la necesidad de cuidar la propia identidad. La teóloga belga Catherine Cornille habla, por ejemplo, de la necesidad de desarrollar unas virtudes características para poder dialogar: humildad, compromiso con la propia tradición, interconexión, empatía y hospitalidad (Catherine CoRnILE, 2008). Por otra parte, el teólogo libanés Michel

${ }^{2}$ Es muy importante-y esperanzador-el trabajo que están realizando diferentes pensadores musulmanes contemporáneos para integrar estos principios políticos en el Islam. Cf. Abdullah Ahmed AN-NA'IM, 2008 y Abdulaziz SACHEDINA, 2009. 
Younès sugiere desarrollar una teología de las religiones sistémica que se elabore teniendo en cuenta las condiciones sociales, muchas veces muy tensas, en que se produce el diálogo (Michel YounĖs, 2015). En todo esto hay algo de la necesidad de alcanzar en el diálogo interreligioso una "segunda ingenuidad", en términos de Paul Ricoeur.

4. Finalmente, para todas las comunidades cristianas este documento debería ser un aldabonazo que nos despertase de nuestro tal vez interesado olvido sobre la realidad de las comunidades de cristianos de Oriente medio. Como antaño los mozárabes en la España musulmana, estas comunidades cristianas han mantenido su fe durante siglos en los países de Oriente medio a pesar de mil vicisitudes, en medio de un entorno culturalmente musulmán, y haciendo del árabe su lengua litúrgica y teológica. De hecho, estas comunidades fueron las primeras comunidades cristianas en desarrollar un diálogo interreligioso con el Islam, diálogo de una enorme fecundidad (GonZÁLEZ CASADO, Pilar, editora 2015). Hoy en día, su presencia en Oriente medio se vuelve muy importante por ser, por una parte, una tercera parte neutral en los conflictos israelo-palestino o sunita-chiita, por otra parte, una comunidad que tiene ya integrada la separación religión-política en una tierra donde esto no es lo normal.

Debemos volver a fijarnos en estas comunidades y sentir sus dolores, no para reforzar una postura identitaria frente al Islam o para justificar nuestras cerrazones, sino para que el diálogo islamo-cristiano, tan necesario en Europa, conecte con sus auténticas raíces en la historia de la Iglesia y para que sea un diálogo que busque la justicia y no sólo una apariencia de ella.

\section{Bibliografía}

AN-NA'IM, A. A. (2008) Islam and the secular State: negotiating the future of Shari'a. Cambridge (Massachusetts, EE.UU.), Harvard University.

CoRnILE, C. (2008) The Im-Possibility of interreligious dialogue, Nueva York, Crossroad.

GonZÁlez CASADO, P., editora (2015) El diálogo de Abrahán de Tiberíades con 'Abd al-Rahman al-Hasimi en Jerusalén hacia el año 820, Madrid, Católica (BAC).

KüNKLER, M. (2013) "Democracy": The Princeton Encyclopedia of Islamic political though, Princeton, Princeton University. 
SACHEDINA, A. (2009) Islam and the Challenge of Human Rights, Nueva York, Oxford University.

VARIOS AUtORES (2012) Pour une théologie chrétienne des religions, París, Desclée de Brouwer.

Younès, M. (2015) "La vocation des chrétiens d'Orient dans leur rapport à l'islam et aux musulmans": Marie-Hélène ROBERT y Michel YOuNĖs, editores (2015) La vocation des chrétiens d'Orient. Défis actuels et enjeux d'avenir dans leurs rapports à l'islam, Paris, Karthala, 45-69.

\section{SALTERRAE}

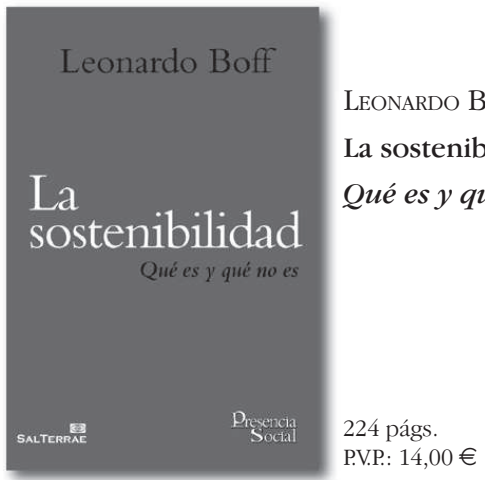

Sobre el Sistema Tierra y el Sistema Vida, incluida la especie humana, pesan graves amenazas originadas por la irresponsable actividad humana, a punto de destruir el frágil equilibrio del planeta. La consecuencia más perceptible es el calentamiento global, que se revela en hechos tan extremos como los tsunamis, las grandes sequías y las devastadoras inundaciones.

Frente a la crisis socioambiental generalizada, la sostenibilidad cons-

tituye una cuestión de vida o muerte. El autor realiza un recorrido histórico desdeel siglo XVI hasta nuestros días, sometiendo a rigurosa crítica los distintos modelos existentes de desarrollo sostenible.

\section{editorial SALTERRAE}

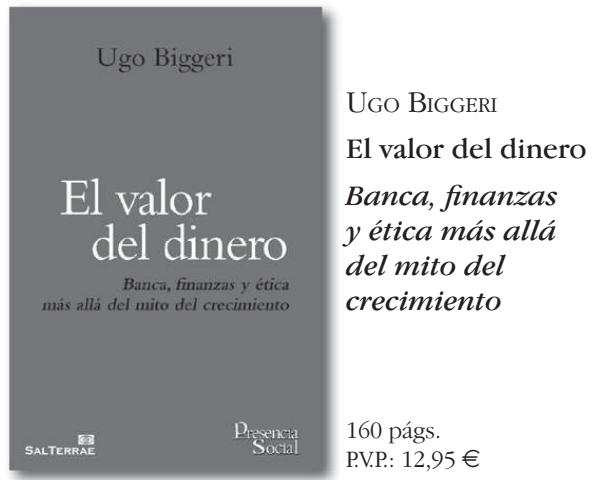

«El valor del dinero no está en el dinero mismo, sino en las personas que lo usan, en las relaciones que favorece, en el bien común que crea».

«¿Qué puedo hacer con mi dinero? Como es obvio, puedo hacer muchas cosas y muy diferentes entre sí, pero la primera de todas es... ihacerme preguntas! Preguntas acerca del dinero, de su significado, de su valor, del valor que tiene para nosotros. Las preguntas acerca del dinero son en nuestros días, lo queramos o no, preguntas sobre la vida» (Ugo Biggeri). 